\title{
Compact and Low-profile Textile EBG-based Antenna for Wearable Medical Applications
}

\author{
A.Y.I. Ashyap, Z. Z. Abidin, Member, IEEE, S. H. Dahlan, Member, IEEE, H. A. Majid, Member, \\ IEEE, S.M. Shah, M. R. Kamarudin, Senior Member, IEEE, A. Alomainy, Senior Member, IEEE.
}

\begin{abstract}
A compact wearable antenna with a novel miniaturized EBG structure at $2.4 \mathrm{GHz}$ for medical application is presented in this letter. The design demonstrates a robust, compact and low-profile solution to meet the requirements of wearable applications. The EBG structure reduces the back radiation and the impact of frequency detuning due to the high losses of human body. In addition, the structure improves the front-to-back ratio (FBR) by $15.5 \mathrm{~dB}$. The proposed compact antenna with dimensions of $46 \times 46 \times 2.4 \mathrm{~mm}^{3}$ yields an impedance bandwidth of $27 \%(2.17-2.83 \mathrm{GHz})$, with a gain enhancement of $7.8 \mathrm{dBi}$ and more than $95 \%$ reduction in the SAR. Therefore, the antenna is a promising candidate for integration into wearable devices applied in various domains, specifically biomedical technology.
\end{abstract}

Index Terms - Artificial ground plane, electromagnetic band gap (EBG), flexible antennas, specific absorption rate (SAR), wearable textile.

\section{INTRODUCTION}

$\mathrm{I}_{\mathrm{N} t e}^{\mathrm{N}}$ $\mathrm{N}$ recent years, increasing interests have been placed on the area of wearable computing systems due to the potential applications in several areas, ranging from health monitoring for elderly/ children, observing human vital signs, physical training, tracking and emergency rescue systems [1]. An antenna plays a vital role in a wearable device. Since such antenna is within a close proximity to the human body with its various curvatures and complexities, the antenna performance must take into account the structural bending, mismatch and losses caused by the body, while at the same time, sustains optimum performance. At the same time, the wearable antenna has to be low-profile, robust and light-weight. The radiation from the wearable antenna should present the least specific absorption rate

This work was supported in part by the Ministry of Education Malaysia (MOE) under Research Accularation Collaborative Effort (RACE) Vot No. 1510 and GPPS Vot. No. U739.

A.Y.I. Ashyap, Z.Z. Abidin, S. H. Dahlan, H. A. Majid and S. M. Shah are with the Research Center for Applied Electromagnetics (EMCenter), Faculty of Electrical and Electronic Engineering, Universiti Tun Hussein Onn Malaysia, (UTHM) Batu Pahat 86400, Johor, Malaysia (e-mail: ashyap2007@gmail.com, zuhairia@uthm.edu.my, samsulh@uthm.edu.my mhuda@uthm.edu.my, and shaharil@uthm.edu.my ).

M R. Kamarudin is with the Centre for Electronic Warfare, Information and Cyber, Cranfield Defence and Security, Cranfield University, Defence Academy of the United Kingdom, Shrivenham, SN6 8LA, UK. (e-mail: ramlee.kamarudin@cranfield.ac.uk).

A. Alomainy is with the Antennas and Electromagnetics Research Group, School of Electronic Engineering and Computer Science, Queen Mary University of London, London E1 4NS, U.K. (e-mail: a.alomainy@qmul.ac.uk).
(SAR) [2] inside the human tissue to adhere to the health and safety requirements. This is applied for several antenna orientations and separation distances from the body.

In the open literature, several designs have been presented and examined for their appropriateness as a wearable antenna element that includes cavity-backed [3], microstrip [4], inverted-F [5], planar and vertical monopole antennas $[6,7]$. However, these antennas have narrow bandwidth, large footprint, high front-to-back ratio and suffering from protrusion from the body.

Alternatively, electromagnetic band gap (EBG) structures are introduced in wearable antenna designs to provide a high degree of isolation from the human body and reduce the SAR in the tissues. However, such structures still suffer from the fact that most EBG-based designs are electrically large [8] - [10], and experiences poor front-to-back ratio [11].

TABLE I

SUMMARY OF THE DIMENSION, THE NUMBER OF UNIT CELLS, DIRECTIVITY PER BANDWIDTH, AND SAR PER DISTANCE VALUE OF THE LITERATURE AT $2.4 \mathrm{GHz}$

\begin{tabular}{|c|c|c|c|c|c|}
\hline \multirow[t]{2}{*}{ Ref } & \multirow[t]{2}{*}{$\begin{array}{l}\text { Dimensions } \\
(\mathrm{mm} 3)\end{array}$} & \multirow{2}{*}{$\begin{array}{l}\text { Number } \\
\text { of unit } \\
\text { cell }\end{array}$} & \multirow{2}{*}{$\begin{array}{l}\begin{array}{l}\text { Directivity } \\
(\mathrm{dBi}) / \\
\mathrm{BW}(\%)\end{array}\end{array}$} & \multicolumn{2}{|c|}{$\begin{array}{l}\text { SAR(w/kg)/ } \\
\text { distance from body }\end{array}$} \\
\hline & & & & $1 \mathrm{~g}$ & $10 \mathrm{~g}$ \\
\hline [9] & $150 \times 150 \times 4$ & $3 \times 3$ & N/A/5.08 & N/A & $0.016 / 1$ \\
\hline [10] & $120 \times 120 \times 4.3$ & $3 \times 3$ & $6.4 / 4$ & $0.079 / 5.3$ & $0.043 / 5.3$ \\
\hline [12] & $100 \times 100 \times 6$ & $2 \times 2$ & $2.42 / 9.85$ & N/A & $0.072 / 15$ \\
\hline [13] & $100 \times 100 \times 4.5$ & $4 \times 4$ & $2.5 / \mathrm{N} / \mathrm{A}$ & N/A & $0.046 / 10$ \\
\hline proposed & $46 \times 46 \times 2.4$ & $2 \times 2$ & $7.8 / 27$ & $0.0368 / 1$ & $0.0138 / 1$ \\
\hline
\end{tabular}

Textile antennas integrated with EBG structures at 2.4 $\mathrm{GHz}$ have been reported in [9]-[10], [12]-[13]. Table I summarizes the work in terms of antenna dimensions, directivity, and SAR performance. From the table, it is evident that the size of the antennas is still large.

In this letter, a low-profile antenna integrated with a compact EBG structure for medical applications is presented. The dimensions are $46 \times 46 \times 2.4 \mathrm{~mm}^{3}$, which demonstrates further size reduction as compared to the previously published work (see Table I) but do not compromise on the performance. The EBG structure is used to produce phase reflection and suppress the surface wave which significantly improve the gain and front-to-back ratio of the antenna and reduces the SAR and consequently, widened the bandwidth.

The design and characterization of the antenna and EBG structure are presented in Section II. In Section III, the analysis of the antenna on EBG plane is discussed. Finally, Section IV examines the antenna-body operation in terms of the reflection coefficient, $S_{11}$, structural bending and SAR. 


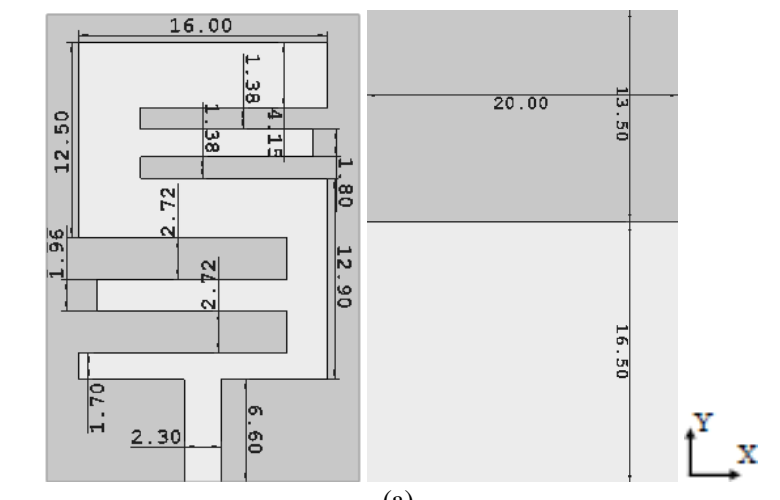

(a)

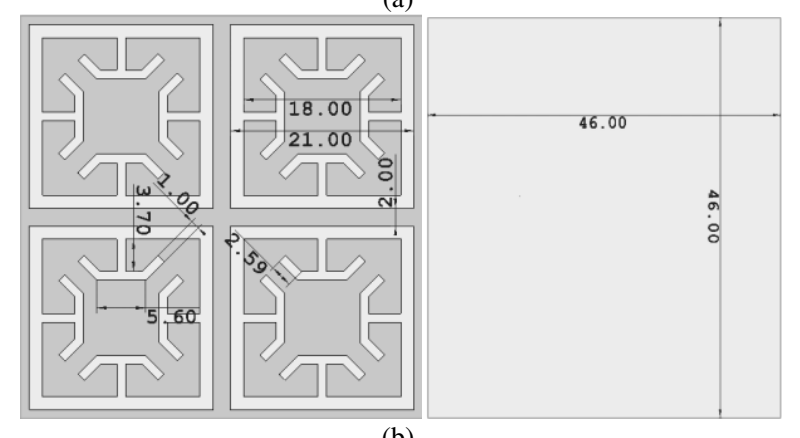

(b)

Fig. 1. Antenna and EBG structure: (a) Top and bottom view of antenna. (b) Top and bottom view of EBG structure. (Unit: mm).

\section{ANTENNA AND EBG DESIGN}

\section{A. Antenna Design}

The proposed inverse E-shaped microstrip monopole antenna is designed numerically by using CST Microwave Studio® [14], to operate at the ISM band of $2.4 \mathrm{GHz}$. The antenna is mounted on a $0.7-\mathrm{mm}$ thick denim material as a substrate with a dielectric constant of 1.7 and loss tangent of 0.02 as illustrated in Fig. 1(a). The overall dimensions of the antenna are $30 \times 20 \times 0.7 \mathrm{~mm}^{3}$ which clearly highlights the compactness of the design as compared to the existing antennas. The conducting material used is ShieldIt Super conductive textile from LessEMF Inc. [15] with thickness of $0.17 \mathrm{~mm}$ and an estimated conductivity of $1.8 \times 10^{5} \mathrm{~S} / \mathrm{m}$ is used to form the metallic layers [13].

\section{B. EBG Design}

In order to achieve a compact EBG structure, a unique square loop patch with four T-shaped connected as strip line pattern is chosen. As mentioned in [16], in order to obtain a compact size, more inductance needs to be introduced into the design. Hence, a strip line pattern is proposed to represent the inductance. The topology of the EBG array is shown in Fig. 1(b). An optimum of $2 \times 2$ EBG array is chosen and placed on a denim material with overall dimensions of $46 \times 46 \times 0.7 \mathrm{~mm}^{3}$. The EBG acts as an artificial magnetic conductor (AMC) when its reflection phase varying from $-180^{\circ}$ to $+180^{\circ}$ and band gap when it is capable to suppress the surface wave at certain operational frequencies.

The analysis of EBG characteristics are performed by using two methods which are the reflection phase and suspended transmission line [17] to validate its performance at the required operating frequency. Fig. 2 depicts the results of the EBG characteristics based on these two methods. It can be observed that the proposed EBG structures can reflect a normally incident electromagnetic wave with a zero phase shift at a frequency of $2.4 \mathrm{GHz}$ which shows the PMC-like characteristic where the PMC characteristic is not exist in nature, while the suspended line examined the band gap of the EBGs from $1.91-2.68 \mathrm{GHz}$ (for $\mathrm{S} 21 \leq-10 \mathrm{~dB}$ ).

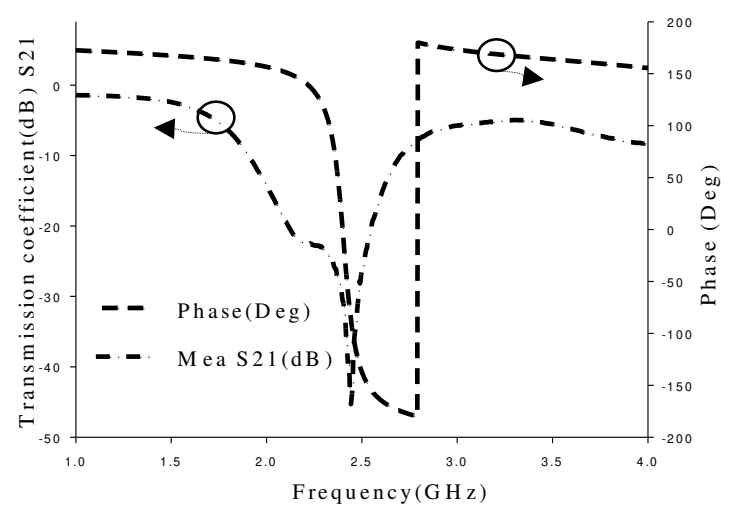

Fig. 2. EBG characteristics based on reflection phase and suspended line.

\section{ANTENNA ON EBG STRUCTURE}

The antenna is placed above the EBG structure as can be viewed in Fig. 3. A 1-mm thick Rohacell foam is employed as a spacer between the antenna and EBG in order to reduce the mismatch and any electrical contacts to prevent from short circuit. It is a highly flexible foam that will take the shape of the surrounding materials it is attached to and will ensure minimum changes to the structure of the antenna applied. Under close inspection, it is found that the foam does not leave much gaps between the substrates.

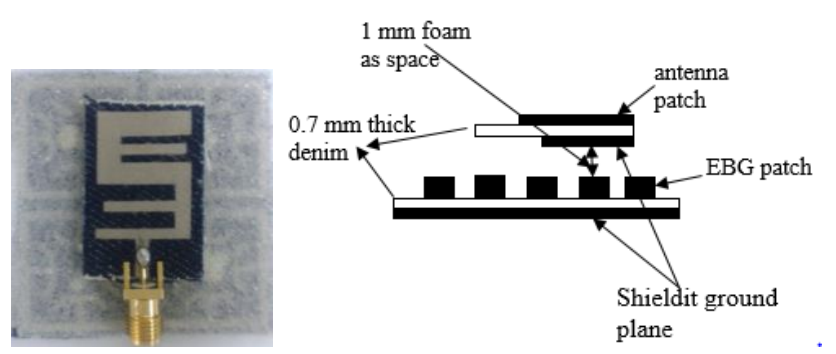

Fig. 3. Configuration of antenna with EBG structure.

The simulated and measured reflection coefficients of the antenna in free space, with and without the EBG structure, are compared as can be seen in Fig. 4. From the figure, the measured band range of the antenna without the EBG structure is from $2.23 \mathrm{GHz}$ to $2.59 \mathrm{GHz}$ with a bandwidth of $360 \mathrm{MHz}(15 \%)$. Meanwhile, the proposed antenna incorporated with EBG effectively enhanced the measured operating bandwidth from $2.17 \mathrm{GHz}$ to $2.83 \mathrm{GHz}$ with a bandwidth of $660 \mathrm{MHz}(27 \%)$. From both results, a good impedance matching is observed with a slight shift in the resonant frequency when the EBG is incorporated. This can be attributed to the inconsistency in the fabrication process and soldering tolerance.

The simulated and measured radiation patterns of the antenna with and without the EBG structure at the E-plane and H-plane are compared as depicted in Fig. 5. The measurement is conducted in the anechoic chamber in the 
UTHM. From the results, a good agreement is shown between the simulated and measured results. The addition of EBG structure reduces the radiation into the human body by at least $15.5 \mathrm{~dB}$ as compared to the antenna by itself and enhances the directivity by up to $7.8 \mathrm{dBi}$ in a direction away from the body.

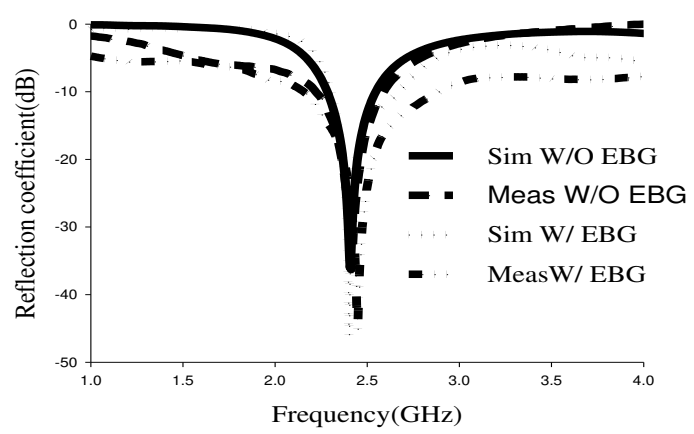

Fig. 4. Simulated and measured reflection coefficient of antenna with and without EBG structure.

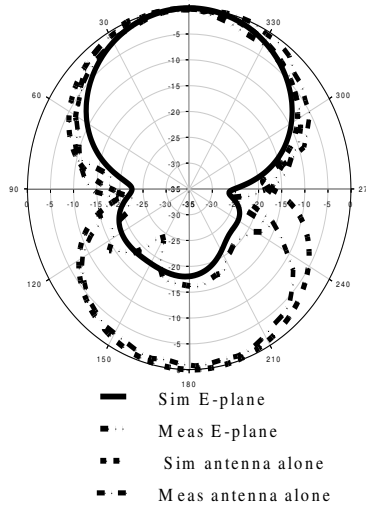

(a)

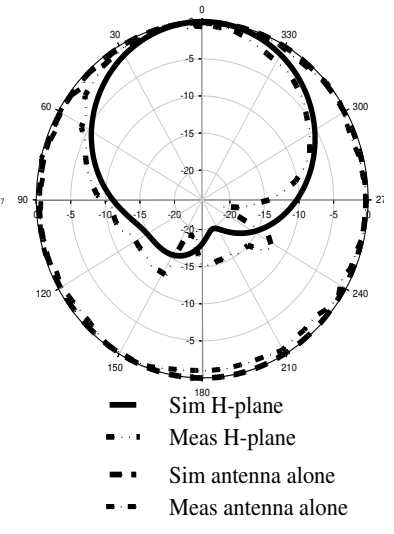

(b)
Fig. 5. Simulated and measured radiation patterns of antenna with and without EBG structure in: (a) E plane (b) H plane.

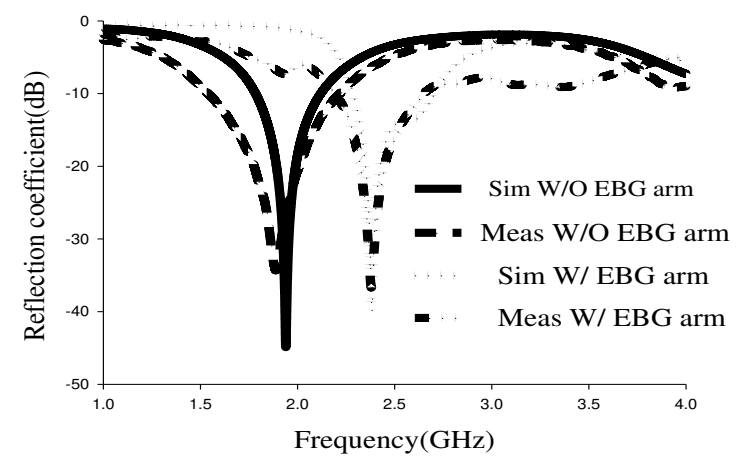

Fig. 6. Simulated and measured reflection coefficient of antenna with and without EBG structure on human arm.

\section{PERFORMANCE OF THE DESIGN ON BODY}

\section{A. Effects of Human Tissues on Reflection Coefficient}

A comparison between the simulated and measured reflection coefficients of the antenna, with and without the EBG structure, is performed to examine the impact of lossy human tissue. A multilayer model with an outer radius of 40 $\mathrm{mm}$ [20] is used to imitate the human tissue model. The model consists of four layers with each layer representing the skin, fat, muscle, and bone. The thickness, permittivity, conductivity, and density of each layer are listed in Table II [21]. The fabricated prototypes were measured on the arm of a male volunteer, who weighs $80 \mathrm{~kg}$ and has a height of 160 $\mathrm{cm}$. The arm radius was $40 \mathrm{~mm}$. The results can be seen in Fig. 6. From the figure, it can be observed that removing the EBG structure causes the shifting of the resonant frequency to the lower band due to the high dielectric nature of human tissue that also influences the response of the antenna which result in the attenuation and detuning [9]. On the contrary, with the presence of EBG, the demanded bands of operation are achieved due to high isolation provided by the EBG between the body and antenna.

\section{B. Bending Evaluation}

The performance of the antenna under deformation is analyzed in this section. In order to do so, a bending of the antenna with EBG structure over a foam cylinder along the $\mathrm{y}$-axis and $\mathrm{x}$-axis in varying diameters (in $\mathrm{mm}$ ), that correspond to the approximate human arm has been modeled. This is to ensure the frequency of operation is sustained under the bending condition as can be seen in Fig. 7. From the figure, the resonant frequency and bandwidth are similar although the diameter of the cylinder is varied.

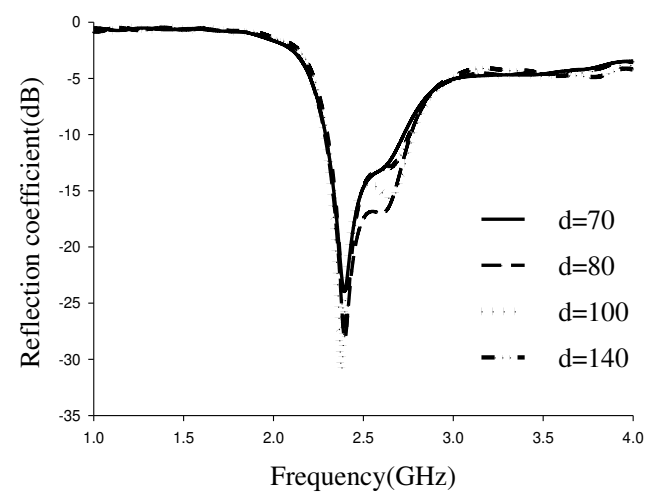

(a)

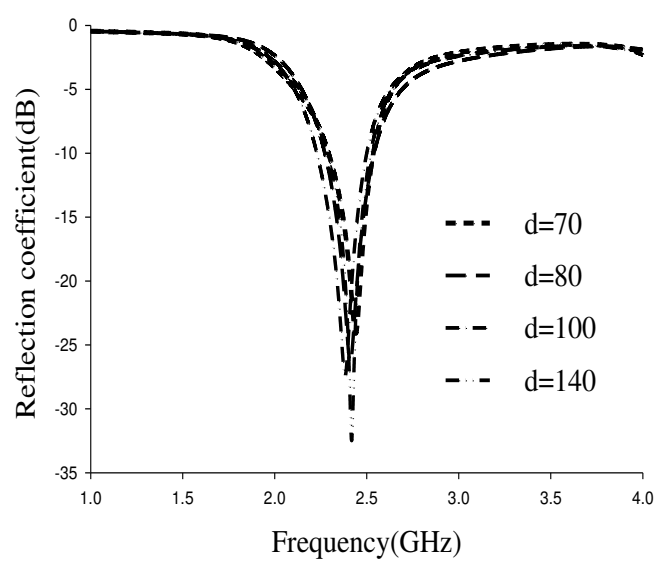

(b)

Fig.7. Reflection coefficient (S11) of antenna with EBG structure for different bending diameters (in $\mathrm{mm}$ ) at the (a) $y$-axis and (b) $\mathrm{x}$-axis

TABLE II MULTILAYER HUMAN MODEL [21]

\begin{tabular}{lcccc}
\hline \hline Layer & $\begin{array}{l}\text { Thickness } \\
(\mathrm{mm})\end{array}$ & $\varepsilon_{r}$ & $\begin{array}{c}\text { Conductivity } \\
\sigma(\mathrm{S} / \mathrm{m})\end{array}$ & $\begin{array}{c}\text { Density } \\
(\mathrm{kg} / \mathrm{m} 3)\end{array}$ \\
\hline Skin & 2 & 37.95 & 1.49 & 1001 \\
Fat & 5 & 5.27 & 0.11 & 900 \\
Muscle & 20 & 52.67 & 1.77 & 1006 \\
Bone & 13 & 18.49 & 0.82 & 1008 \\
\hline \hline
\end{tabular}




\section{Specific Absorption Rate Evaluation}

The SAR level of the antenna, with and without the EBG structure, needs to be analyzed in the design stage to ensure the safety limit is obeyed. According to the guidelines by the FCC and CNIRP, the SAR must not be greater than $2 \mathrm{~W} / \mathrm{kg}$ averaged over $10 \mathrm{~g}$ and not greater than $1.6 \mathrm{~W} / \mathrm{kg}$ averaged over $1 \mathrm{~g}$ of human tissues [18 - 19].

The same multi-layer model that was explained in the previous section was used for SAR analysis. The model consists of four layers with each layer representing the skin, fat, muscle, and bone. The thickness, permittivity, conductivity, and density of each layer are listed in Table II [21].

The input power to the antenna to calculate the SAR is selected at $100 \mathrm{~mW}$ as a benchmark. In addition, to emulate the practical antenna to skin distances in fabric, a $1 \mathrm{~mm}$ distance between the antenna with EBG structure and the multilayer model tissues are used. The calculation of SAR is based on the IEEE C95.1 standard provided in the CST MWS software.

As shown in Table III, the SAR values of the antenna with EBG structure obey both standards. The reduction is more than $95 \%$ and is compared with the previous published data as shown in Table I.

TABLE III

SAR VALUES WITH AND WITHOUT EBG

\begin{tabular}{ccc}
\hline \hline Averaged value & $\begin{array}{c}\text { SAR without EBG } \\
(\mathrm{w} / \mathrm{kg})\end{array}$ & $\begin{array}{c}\text { SAR with EBG } \\
(\mathrm{w} / \mathrm{kg})\end{array}$ \\
\hline $1 \mathrm{~g}$ & 6.19 & 0.0368 \\
$10 \mathrm{~g}$ & 2.70 & 0.0138 \\
\hline \hline
\end{tabular}

\section{CONCLUSION}

A novel compact wearable antenna with a miniaturized EBG structure for medical applications is successfully designed, simulated and measured. The EBG structure is used to eliminate the mismatch and frequency shifting caused by the human body. In addition, the presence of the EBG structure reduces the unwanted radiation towards the human body. The bending do not affect the resonant frequency and bandwidth of the antenna. The proposed design exhibits an operating bandwidth of $27 \%$ and a gain of $7.8 \mathrm{dBi}$ at $2.4 \mathrm{GHz}$. The front-to-back ratio improves by $15.5 \mathrm{~dB}$. Furthermore, the calculated SAR values are low and obey the limit stipulated in the FCC and CNIRP regulations. Thus, the proposed antenna with EBG structure is a strong potential candidate for wearable medical applications.

\section{REFRENCES}

[1] H. Yang, W. Yao, Y. Yi, X. Huang, S. Wu, and B. Xiao, "A dualband low-profile metasurface-enabled wearable antenna for WLAN devices," Progress In Electromagnetics Research C, vol. 61, no. January, pp. 115-125, 2016.

[2] R. A. Abd-Alhameed, P. S. Excell, and M. A. Mangoud, "Computation of specific absorption rate in the human body due to base-station antennas using a hybrid formulation," IEEE Trans. Electromagn. Compat. vol. 47, no. 2, pp. 374-381, May 2005.

[3] N. Haga, K. Saito, M. Takahashi, and K. Ito, "Characteristics of cavity slot antenna for body-area networks," IEEE Trans. Antennas Propag., vol. 57, no. 4, pp. 837-843, Apr. 2009.
[4] A. Alomainy, Y. Hao, A. Owadally, C. G. Parnini, Y. Nechayev, C. C. Constantinou, and P. S. Hall, "Statistical analysis and performance evaluation for on-body radio propagation with microstrip patch antennas," IEEE Trans. Antennas Propag., vol. 55, no. 1, pp. 245 248, Jan. 2007.

[5] P. J. Soh, G. A. E. Vandenbosch, S. L. Ooi, and N. M. A. Rais, "Design of a broadband all-textile slotted PIFA," IEEE Trans. Antennas Propag., vol. 60, no. 1, pp. 379-384, Jan. 2012.

[6] M. N. Suma, P. C. Bybi, and P. Mohanan, "A wideband printed monopole antenna for $2.45 \mathrm{GHz}$ WLAN applications," Microw. Opt.Technol. Lett., vol. 48, no. 5, pp. 871-873, May 2006.

[7] Y. I. Nechayev, P. S. Hall, and Z. H. Hu, "Characterization of narrowband communication channels on the human body at 2.45 GHz," IET Microw. Antennas Propag., vol. 4, no. 6, pp. 722-732, June 2010.

[8] K. Kamardin, M. K. A. Rahim, P. S. Hall, N. A. Samsuri, T. A. Latef, and M. H. Ullah, "Planar textile antennas with artificial magnetic conductor for body-centric communications," Appl. Phys. A Mater. Sci. Process., vol. 122, no. 4, pp. 1-9, 2016.

[9] S. Velan, E. F. Sundarsingh, M. Kanagasabai, A. K. Sarma, C. Raviteja, R. Sivasamy, and J. K. Pakkathillam, "Dual-band EBG integrated monopole antenna deploying fractal geometry for wearable applicaitons", IEEE Ant. Wire. Propag. Lett. Vol. 14, pp. 249-252, 2015.

[10] S. Zhu and R. Langley, "Dual-band wearable textile antenna on an EBG substrate," IEEE Trans. Antennas Propag., vol. 57, no. 4, pp. 926-935, Apr. 2009.

[11] H. R. Raad, A. I. Abbosh, H. M. Al-Rizzo, and D. G. Rucker "Flexible and compact AMC based antenna for telemedicine applications," IEEE Trans. Antennas Propag., vol. 61, no. 2, pp. 524 531, Feb. 2013.

[12] H. Lago, P. J. Soh, M. F. Jamlos, N. Shohaimi, S. Yan, and G. A. E. Vandenbosch, "Textile antenna integrated with compact AMC and parasitic elements for WLAN/WBAN applications," Appl. Phys. A, vol. 122, no. 12, pp. 1059-1062, 2016.

[13] S. Yan, P. J. Soh, and G. A. E. Vandenbosch, "Low-profile dual-band textile antenna with artificial magnetic conductor plane," IEEE Trans. Antennas. Propag., vol. 61, no. 12, pp. 6487-6490, Dec. 2014.

[14] CST Microwave Studio [Online]. Available: http/www.cst.com

[15] Specification Sheet-ShieldIt Super LessEMF Inc., 2013.

[16] L. Kurra, M. P. Abegaonkar, A. Basu, and S. K. Koul, “A compact uniplanar EBG structure and its application in band-notched UWB filter," Int. J. Microw. Wireless Technol., vol. 5, no. 4, pp. 491-498, 2013.

[17] A. Aminian, F. Yang, and Y. Rahmat-Samii, "In-phase reflection and EM wave suppression characteristics of electromagnetic band gap ground planes," in Proc. IEEE Antennas Propag. Soc. Int. Symp., vol. 4, pp. 430-433, Jun 2003.

[18] A. Ahlbom., U. Bergqvist., J. H. Bernhardt., J. P. Cesarini., M Grandolfo., M. Hietanen., A. F. Mckinlay., M. H. Repacholi., D. H. Sliney., J A. J. Stolwijk. "Guidelines for limiting exposure to timevarying electric, magnetic, and electromagnetic fields (up to 300 GHz)," International Commission on Non-Ionizing Radiation Protection, Heal. Phys, vol. 74, no. 4, pp. 494-522, 1998.

[19] IEEE Recommended Practice for Measurements and Computations of Radio Frequency Electromagnetic Fields with Respect to Human Exposure to Such Fields, 100 kHz-300 GHz, IEEE Std C95.3-2002, (Revision of IEEE Std C95.3-1991), vol., no., pp.i-126, 2002.

[20] Z. Jiang, D. E. Brocker, P. E. Sieber, and D. H. Werner, "A compact, low-profile metasurface-enabled antenna for wearable medical bodyarea network devices," IEEE Trans. Antennas Propag., vol. 62, no. 8, pp. 4021-4030, Aug. 2014

[21] M. A. Stuchly and S. S. Stuchly, "Dielectric properties of biological substances-tabulated," J. Microw. Power, vol. 15, no. 1, pp. 19-26, Jan. 1980. 